\title{
IMAGINARIO EN CARTAS: APRENDIZAJE MUSICAL COLABORATIVO Y CUENTACUENTOS EN LA FORMACIÓN DE PROFESORES
}

\author{
IMAGINARY IN LETTERS: COLLABORATIVE MUSICAL LEARNING AND \\ ACCOUNTS IN THE TRAINING OF TEACHERS
}

\author{
Antenor Rita Gomes \\ Universidad del Estado de Bahía, Brasil \\ http://orcid.org/0000-0002-4386-0305 \\ antenorritagomes@gmail.com
}

Eliandra Cardoso dos Santos Vendrame
Universidade Estadual de Maringá, Brasil
https://orcid.org/0000-0002-6212-0847
eliandravendrame@gmail.com

Andreia Pires Chinaglia de Oliveira Universidade Estadual de Maringá, Brasil https://orcid.org/0000-0003-4654-708X maiandpoliveira@hotmail.com

Recibido: 22-01-2020 Revisado: 19-02-2020 Aceptado: 01-03-2020

Resumen: El propósito de este texto es registrar la relación de las cartas con lo imaginario, en la investigación y en la formación del profesorado, para relacionar el aprendizaje colaborativo y la narración de historias con el desempeño profesional y el (re) significado del desempeño. La metodología se realizó con la propuesta de redacción de cartas, en dos situaciones de investigación con formación docente, una en formación inicial y otra en formación continua, ambas realizadas en Paraná, Brasil. El imaginario fue retratado en dos objetos, el aprendizaje musical colaborativo con el curso de extensión "Jugando y Cantando" y la narración a través del curso de extensión "Ponerse en la rueda: capacitación de maestros de narración de cuentos". Las cartas revelan la comunicación en el intercambio de información y conocimiento, lo que presupone una relación entre uno mismo y el otro. Considera que la formación de docentes, con el apoyo de experiencias, contribuye a la (re)organización de acciones dirigidas al desarrollo humano.

Palabras clave: Cartas, música, cuentacuentos, formación de profesores.

\begin{abstract}
The purpose of this text is to record the relationship of the letters with the imaginary, in research and teacher training, to relate collaborative learning and storytelling to professional performance and the (re) meaning of performance. The methodology was carried out with the proposal of writing letters, in two research situations with teacher training, one in initial training and another in continuous training, both conducted in Paraná, Brazil. The imaginary was portrayed in two objects, the collaborative musical learning with the extension course "Brincando e Cantando" and the narration through the extension course "Get on the wheel: training of storytelling teachers". The letters reveal communication in the exchange of information and knowledge, which presupposes a relationship between oneself and the other. Believes that teacher training, with the support of experiences, contributes to the (re) organization of actions aimed at human development.
\end{abstract}

Keywords: Letters, storytelling, music, teacher training 
Cómo citar este artículo: Gomes, A. R., Vendrame, E. C. dos S. y Oliveira, A. P. C. (2020). Imaginario en cartas: aprendizaje musical colaborativo y cuentacuentos en la formación de profesores. Hachetetepé. Revista cientifica en Educación y Comunicación, (20), 17-30. doi: http://doi.org/10.25267/Hachetetepe.2020.i20.4

\section{INTRODUCCIÓN}

En medio de los diversos instrumentos formales y algo "cerrados" en los que se presenta la investigación con respecto a la recopilación de datos, la producción de cartas se presenta como una nueva "amanecer" en la articulación entre los idiomas académicos, coloquiales y cotidianos. La investigación de Moraes y Castro (2018) señala que las cartas pedagógicas son una valiosa herramienta de investigación para expresar verdades, sentimientos y confesiones reveladas solo a aquellos destinados.

Las cartas pedagógicas pueden configurarse en esta investigación como un proceso de experimentación e innovación en la investigación que tiene el campo artístico como la producción de conocimiento. Las cartas son una forma más directa de comunicación entre una relación de una persona consigo mismo y con los demás y una herramienta pedagógica que es fácil de usar y puede ser bastante diversa y tener varios significados y sentidos: personal, afectivo, informativo, etc.

Una de las características principales de una carta es el hecho de que se cree, espontáneamente, que le permite al escritor tomar la distancia para reflexionar, retomar una oración antes de lanzarla al destinatario, releer el texto para comprender mejor su significado anunciando la verdad de una experiencia del autor. Para entrelazar lo imaginario en las cartas, seguiremos la estructuración de este texto con los estudios realizados en la formación inicial y continua de los docentes, en los que las cartas fueron instrumentos de significado de las experiencias.

\section{APRENDIZAJE MUSICAL COLABORATIVO EN LA FORMACIÓN INICIAL DEL PROFESORADO DE MÚSICA Y ARTES ESCÉNICAS}

La música tiene un carácter estético y subjetivo y, a través de la Educación Musical, un área de conocimiento del proceso educativo y de capacitación, el individuo tiene acceso a este lenguaje. Por lo tanto, musicalizar a una persona, ya sea de cualquier grupo de edad, es darle herramientas básicas para que no solo pueda apreciar, sino interpretar, aprender, crear y relacionarse con los elementos musicales. Las investigaciones más reciente sobre el aprendizaje colaborativo en educación (Goodsell, Maher, Tinto, 1992; Smith y Macgregor, 1992; Marsh, 2008; 2013; Comério y Brito, 2010; Ribeiro y Ramos, 2012; Renshaw, 2013; Troncareli y Faria, 2014; Torres y Irala, 2014; Oliveira, 2015; Fugimoto, 2015; Gabriel, 2016; Graça, 2016; Bezerra, 2017; Gonzaga, 2017; Machado, 2017) definen que surge de un diálogo activo y de la exposición de ideas de participantes en un grupo que interactúan entre sí en el proceso de construcción de conocimiento.

Para que esto suceda, el papel del maestro es muy importante y va más allá de reunir a los estudiantes y pedirles que trabajen juntos. Necesita actuar como mediador, con intervenciones estructuradas y tareas bien diseñadas para que los resultados sean positivos. El aprendizaje colaborativo va más allá de ser una metodología.

Por lo tanto, el maestro que utiliza el aprendizaje colaborativo debe haberlo experimentado y experimentado en su formación inicial y en su proceso de formación 
como persona, pero esta no es la realidad de nuestros cursos de pregrado, muchos de los cuales todavía están basados en modelos y metodologías obsoletas.

En esta investigación, Collaborative Learning se utilizó como una propuesta de capacitación innovadora y creativa para contribuir a la práctica docente de los estudiantes de música y artes escénicas, temas de la investigación, a fin de permitir una experiencia docente que escuche la voz de los estudiantes y, por lo tanto, cambie el papel tanto el profesor como el alumno en busca de un aprendizaje más activo y comprometido, con todos los involucrados en los procesos de enseñanza y aprendizaje.

\section{ENFOQUES METODOLÓGICOS EN EL IMAGINARIO DEL APRENDIZAJE MUSICAL COLABORATIVO}

En vista de estas consideraciones mencionadas anteriormente, en 2019, se preparó el curso de extensión. "Jugando y Cantando". Este curso es una acción del proyecto de extensión de Música, Escuela y Comunidad ofrecido por el Departamento de Música de la UEM desde 2010. Cada año, el curso atiende a un promedio de 30 niños de la comunidad externa con clases colectivas de canto, así como espacio para la formación académica del curso de educación musical en la UEM.

Para el año 2019, el curso tuvo lugar entre abril y diciembre, con una carga de trabajo total de 30 horas y tuvo como objetivo desarrollar un teatro musical con niños a través del aprendizaje colaborativo. Para esto, además de los 7 graduados en educación musical que impartieron clases de música, tuvimos 4 graduados en artes escénicas para desarrollar actividades relacionadas con los detalles del teatro. Tanto los académicos de música como las artes escénicas realizaron un trabajo integrado y colaborativo para que cada uno pudiera actuar en su área y colaborar para la realización del conjunto.

Con el objetivo de investigar cómo contribuye el aprendizaje colaborativo, tanto en la formación académica y la práctica docente de los estudiantes, como en la apropiación del aprendizaje musical de los niños, la investigación cualitativa (Gray, 2012) obtuvo los datos generados por el contacto directo e interacción entre el investigador y el objeto estudiado, lo que permitió profundizar la comprensión de los fenómenos estudiados desde la complejidad y vivacidad de las acciones de los individuos en las prácticas musicales, en las interacciones de los sujetos y en sus percepciones en el uso del aprendizaje colaborativo, modificando en el proceso.

Para este artículo, la atención se centra en la capacitación inicial, por lo que se resaltará la perspectiva de los profesores académicos en la producción de cartas.

Se invitó a los académicos (profesorado) a elegir un nombre ficticio para poder identificarlos en la investigación y no revelar sus identidades de acuerdo con el término firmado por ellos en el documento de aceptación de la investigación. Sin embargo, algunos querían mantener sus nombres reales, los nombres que aparecen en la tabla con * se han cambiado. 
Tabla 1

Académicos que participan en la investigación.

\begin{tabular}{|c|c|c|c|}
\hline NOMBRE/IDENTIFICACIÓN & EDAD & CURSO & SERIE \\
\hline Cora* & 18 & $\begin{array}{l}\text { Licenciatura en Educación } \\
\text { Musical }\end{array}$ & $1^{\circ}$ \\
\hline Marcio* & 18 & Licenciado en Artes Escénicas & $1^{\mathrm{o}}$ \\
\hline Nobélia* & 25 & $\begin{array}{l}\text { Licenciatura en Educación } \\
\text { Musical }\end{array}$ & $2^{\circ}$ \\
\hline Fernanda & 18 & $\begin{array}{l}\text { Licenciatura en Educación } \\
\text { Musical }\end{array}$ & $1^{\mathrm{o}}$ \\
\hline Dora* & 18 & $\begin{array}{l}\text { Licenciatura en Educación } \\
\text { Musical }\end{array}$ & $1^{\mathrm{o}}$ \\
\hline Clara Luz* & 20 & $\begin{array}{l}\text { Licenciatura en Educación } \\
\text { Musical }\end{array}$ & $2^{\circ}$ \\
\hline Castiel* & 22 & Licenciado en Artes Escénicas & $3^{\circ}$ \\
\hline Bruna & 20 & Licenciado en Artes Escénicas & $3^{\circ}$ \\
\hline Gustavo & 20 & Licenciado en Artes Escénicas & $3^{\circ}$ \\
\hline Isabel & 19 & $\begin{array}{l}\text { Licenciatura en Educación } \\
\text { Musical }\end{array}$ & $1^{\mathrm{o}}$ \\
\hline Rafa & 21 & $\begin{array}{l}\text { Licenciatura en Educación } \\
\text { Musical }\end{array}$ & $4^{\mathrm{o}}$ \\
\hline
\end{tabular}

Fuente: elaboración propia, 2020

Para comprender las diferentes perspectivas de los académicos, sus acciones pedagógicas, sus discursos y acciones, se eligieron 4 instrumentos de recopilación de datos: 1) Observación participante (Angrosino, 2008; Freire, 2010; Gray, 2012) con grabación de video y elaboración de diario de campo en el laboratorio de formación pedagógica; 2) Observación de participantes (Angrosino, 2008; Freire, 2010; Gray, 2012) con grabación de video y elaboración del diario de campo en las clases del curso de extensión; 3) Círculos de conversación (Warschauer, 2017a; 2017b); 4) Producción de cartas (Moraes y Paiva, 2018; Moraes y Castro, 2018; Paula, 2018). En esta investigación, las letras fueron un recurso visual importante.

Las cartas se prepararon después de la reunión del círculo de conversación a fines de agosto de 2019. Para que los académicos entiendan la dinámica y tengan un estímulo de escritura, se preparó una carta para cada uno de ellos. Por lo tanto, se les pidió que respondieran a la carta recibida e imprimieran sus sentimientos, opiniones y percepciones en relación con: momentos de estudios teóricos sobre aprendizaje colaborativo; la aplicación en ese contexto de actividades prácticas de colaboración sugeridas por nosotros y por los académicos; las prácticas de elaborar la planificación de las clases del curso de extensión de manera colaborativa; y, finalmente, reflexiones sobre sus acciones y el aprendizaje de los niños.

4. IMAGINARIO EN LOS RECUERDOS NARRADOS EN CARTAS: EL ENCANTO DEL APRENDIZAJE COLABORATIVO Y "SER MAESTRO"

A partir de la redacción de las cartas, se presentará la percepción de los estudiantes en relación con dos puntos: aprendizaje colaborativo; impactos del aprendizaje colaborativo en su formación inicial. En cuanto al aprendizaje colaborativo, fueron puntuales en sus notas. Pudieron experimentar la teoría basada en mucha vivacidad y, 


\section{Hachetetepé. Revista científica de Educación y Comunicación}

$\mathrm{N}^{\mathrm{o}} 20,17-30,2020$

como la investigación ya mencionada, se dieron cuenta de la importancia de "escuchar a los niños", porque, además de motivarlos a estar siempre en clase, había una mayor participación y compromiso en las actividades. y en la preparación del teatro musical:

Aprendí, al igual que los niños, que trabajar juntos funciona. Escuchar / aceptar diferentes opiniones hace que el trabajo fluya. (Marcio)

Este método hizo que los niños se sintieran más importantes simplemente dando sus propias opiniones. (Cora)

El aprendizaje colaborativo hace que las clases sean más enriquecedoras, permite a los estudiantes colaborar en el aprendizaje y estimular su creación. (Nobélia)

Además, expresaron cuánto rompe el aprendizaje colaborativo con los modelos de enseñanza tradicionales y es una alternativa a la situación actual en la que se encuentra nuestra educación hoy:

La metodología es interesante porque deja los estándares de aprendizaje al permitir que los niños tengan una voz que dé su opinión. (Isabel)

Siempre he creído en una educación emancipadora y esta metodología cumple con eso (Rafa)

Estas declaraciones son valiosas en la investigación, ya que nos muestran que el aprendizaje colaborativo puede ser una metodología innovadora consistente con el carácter colaborativo que las artes nos presentan. Por lo tanto, la importancia de fomentar cada vez más este tipo de aprendizaje y enseñanza dentro del contexto académico como modelo de formación.

En este sentido, ingresamos al segundo punto destacado para el análisis en este artículo, que se señaló en las cartas, que es el impacto del aprendizaje colaborativo en la capacitación inicial. Se percibió un momento de gratitud y sentimiento de parte de los académicos. Algunos que no hablaron mucho, se expresaron mejor a través de la carta y pudieron imprimir sus percepciones de manera profunda:

Agradezco la oportunidad de unirme a esta extensión en la que me encanta participar. Pude tener experiencias que estoy tomando para mi desarrollo docente. Siento que el trabajo que hemos realizado me motiva a continuar en el área de la educación y me doy cuenta de que no soy el único motivado. (Dora)

Gracias por aceptarme con los brazos abiertos en esta extensión. Aunque era estudiante de primer año, pude ver en el área de estudios de pregrado, que no era mi objetivo antes, que el trabajo realizado cambió mi perspectiva de lo que podría ser una clase. La situación en que se encuentran los educadores de nuestro país desalienta a muchos estudiantes. Sin embargo, con este proyecto tuve la oportunidad de probar el título. (Marcio)

Teniendo en cuenta estas notas, vemos no solo las características del aprendizaje colaborativo presente, sino también lo importante que es presentarlo y experimentarlo con los académicos en la formación, no solo como una metodología de enseñanza, sino como una filosofía de vida, tal como nos enseña Torres e Irala (2014). Es necesario creer que su uso es posible y factible en busca de una educación más humana y social, tanto para docentes como para estudiantes. 


\subsection{Cuentacuentos en la formación del profesorado}

Al pensar en la educación inicial (de pregrado) y continua de maestros y narradores, es necesario considerar la participación activa de los maestros en su trayectoria de Educación Literaria. Esta participación no puede registrarse sin tener en cuenta sus elecciones profesionales, sus recuerdos y las historias de la infancia que forman parte de los recuerdos afectivos en relación con la literatura infantil y las experiencias de los procesos de formación docente para actuar con la educación de la primera infancia. En vista de estas consideraciones, la Universidad Estatal de Maringá (UEM) desarrolló un curso de extensión en colaboración con el departamento de educación municipal del municipio de Campo Mourão, en el Medio Oeste de Paraná, y el Programa Multidisciplinario de Estudios, Investigación y Defensa de Niño y adolescente - PCA / UEM, el curso tuvo lugar en 2019, con una carga de trabajo de 30 horas, con la participación de 21 docentes de educación infantil en la red municipal.

La búsqueda de comprender la relación entre la enseñanza y el proceso de educación continua de los docentes como narradores, a través de la capacitación / estudios y experiencias, se ha convertido en una fuente de conocimiento sobre el proceso de construcción de la identidad y la subjetividad de los docentes en educación y en sus propias vidas. Este aspecto se evidencia en la declaración de Oliveira (2006), que describe "Narrar su historia es una forma en que cada persona puede dar sentido a su experiencia, dar sentido a quienes son y darse cuenta de cómo se construye en el mundo social" (Oliveira, Silva, Cardoso y Augusto, 2006, p.552)

Comprender la importancia de la formación del profesorado y su relación con la literatura infantil nos permite considerar que las historias en la educación literaria son importantes para que los docentes no solo aprendan algo o tengan recursos pedagógicos, sino que sientan la emociones y sensaciones del arte, que entienden que en la literatura infantil hay palabras que pueden llevarlos a otros lugares, que pueden encantar y hacer que la imaginación traiga sueños. En este sentido, la educación literaria "tiene como objetivo proporcionar al lector un conocimiento relevante sobre textos, autores, géneros, así como convenciones, temas y estilos literarios para que pueda sentirse un miembro activo y participante en un hogar común”. (Azevedo y Balça, 2016, p.2)

En el curso de la formación del otro y de sí mismo, el profesor, al estudiar los aspectos literarios, comprende que la narración de cuentos es uno de los recursos utilizados por los seres humanos para reproducir la cultura, reinventarla y, por lo tanto, posibilitar la imaginación, la fantasía y la diversión, aspectos significativos para la educación literaria.

\subsection{Referencias metodológicas y el imaginario de la narración.}

La formación docente descrita en esta sección del trabajo es una investigación cualitativa basada en la metodología de investigación de acción. El curso de extensión, que se refiere a la educación continua de los maestros, fue gratuito, con la participación de 21 maestros de preescolar de la red pública de Campo Mourão. El proyecto del curso de extensión fue presentado al Comité de Ética e Investigación y fue debidamente aprobado.

Las reuniones de este curso de capacitación se llamaron talleres, y se construyeron sobre la práctica interactiva y reflexiva desarrollada con maestros en círculos de conversación, círculos culturales, clases teórico-prácticas que pretenden constituir, en sí mismas, un campo de estudio propio. El campo de este estudio, por lo tanto, fue un grupo 
de maestros de Educación Infantil, maestros en el Municipio de Campo Mourão-Paraná. Estos profesionales son responsables de las clases de arte, literatura, filosofía y psicomotricidad que trabajan con el preescolar. Los temas de investigación provienen de una invitación hecha por el Departamento Municipal de Educación que, en asociación con la Universidad Estatal de Maringá, ofreció el curso de extensión llamado "Ponerse en la rueda: Formación de maestros de narración de cuentos".

El curso se ofreció a los maestros con 30 horas, 20 horas de capacitación grupal, con 5 reuniones de 4 horas, cada reunión, en las que se desarrollaron estudios y talleres para preparar materiales para contar historias en diferentes contextos. Y después de las producciones y elaboraciones, los grupos hicieron las aplicaciones de las historias en sus escuelas y en un grupo no escolar. Estos 2 momentos de acción duraron 3 horas, se realizó una última reunión colectiva, que duró 4 horas, para socializar las experiencias durante el desarrollo de esta capacitación. En el enfoque de investigación cualitativa, la recopilación de datos incluyó registros descriptivos, que permitieron el análisis y la interpretación. Uno de los pasos y registros fue la escritura de dos cartas, una al principio y otra al final del curso, escritas por los maestros, durante el curso.

Para promover el análisis de las experiencias literarias de los maestros con la narración de cuentos, durante la infancia y en el proceso de capacitación académica inicial y continua, se les pidió a los participantes en el Curso de Extensión que escribieran una carta inicial que sugiriera pensar en la infancia y las historias. Para eso, los maestros recibieron una carta por correo, que fue enviada por el investigador, durante el intervalo de la primera a la segunda reunión, contenía un guion, con preguntas para registrar aspectos de la narración, en la Educación Literaria de los maestros. Para este artículo, la atención se centrará en dos preguntas, que estaban presentes en el guion, cuyas respuestas fueron analizadas: ¿Quién te presentó al universo de la literatura? ¿Qué historia marcó tu infancia?

El grupo formado por 21 participantes estaba compuesto por 19 maestras y 2 maestros. Cada uno de ellos eligió, durante una conversación, un nombre relacionado con el personaje de una de las historias que le gusta e identifica, que presentamos en la siguiente tabla:

\section{Tabla 2}

Identificación de los sujetos en la investigación

\begin{tabular}{cc}
\hline MI PERSONAJE & HISTORIA RELACIONADA \\
\hline Emília & O Sítio do Pica Pau Amarelo \\
Anna Llnas & Os monstros das cores \\
Miudinha & Peripécias da Princesa Miudinha \\
Rei da Floresta & O Leão e o Ratinho \\
Rita & Balão Vermelho \\
Alice & Bambi \\
Anjo & Apocalipse \\
Inha Zabé & Mãe Clementina \\
Disquinho & Coleção Disquinho \\
Sandra & Os sete Cabritinhos \\
Chapeuzinho Vermelho & Chapeuzinho Vermelho \\
Maria & Maria vai com as outras \\
A gata Borralheira & A gata Borralheira \\
Rouxinol & O pequeno Roxinol
\end{tabular}


Vagalume Bela

Banqueiro

Barbie

Arco-íris

Branca de Neve

Margarida
Série Vagalume

A Bela e a Fera

Vó Nana

As três mosqueteira

Bom dia todas as cores - Ruth Rocha

Branca de Neve

Margarida Friorenta

Fuente: elaboración propia, 2020

Vale la pena señalar que los nombres fueron elegidos en medio de una reflexión sobre la historia que los participantes recordaron y que les dijeron, algunos nombres seleccionados, presentes en el cuadro 2, están relacionados con el narrador y la indicación de la historia que se presentó en el infancia al tema de esta investigación. Este es el caso de la participante "Sandra", que no es el personaje de la historia, sino la madre de la maestra, que en este caso fue su narradora. Del grupo de participantes, 3 maestros no entregaron la carta inicial, ellos fueron: Anna Llnas; Miudinha e Bela.

\subsection{El imaginario y los recuerdos narrados en cartas: ¿quién te presentó el universo de la literatura? ¿Qué historia marcó tu infancia?}

El universo imaginario está lleno de recuerdos e historias, así como la frase de Vigotski, "Toda imaginación siempre tiene una historia muy larga" (Vigotski, 2009, p.35). Imaginar requiere pensar en su propia historia, y recordar la infancia tiene un significado importante en la trayectoria de la enseñanza. En el contexto del intercambio de información y conocimiento, la carta presupone más directamente una relación entre uno mismo y el otro. Este recurso, instiga la lectura, ya que se refiere a la idea que estamos prescribiendo, pasando por los "secretos" del remitente; una carta dada, dirigida al destinatario específico. Es precisamente la intención de la referencia a las cartas en la composición de este texto, ya que:

[...] toda memoria es fundamentalmente "creación del pasado": una reconstrucción comprometida del pasado (a menudo subversiva, rescatando la periferia y los marginados) y que juega un papel fundamental en la forma en que los grupos sociales más heterogéneos aprehenden el mundo actual y reconstruyen su identidad, insertándose en las estrategias de reclamo para un derecho complejo de reconocimiento (Seixas, 2001, p.89)

En esta perspectiva, las cartas que recibimos inicialmente permiten el análisis de cómo los maestros reconstruyen sus recuerdos en relación con el mundo imaginario y su reconocimiento. Lo que corrobora la propuesta de Batista y Paula (2019, p.75): "Las cartas informales son narraciones que revelan subjetividades, percepciones y valores sobre el mundo y la sociedad". En cierto modo, que en la carta inicial los participantes informan sobre temas de su educación literaria, en medio de narraciones, esto sugiere que "A través de las cartas, las personas narran sus vidas, recuerdos e historias" (Batista y Paula, 2019, p.75), reconstruyendo así sus historias, su imaginario. A continuación, estos registros se anotan en los extractos de las cartas de los maestros: "Mi historia con el mundo imaginario comenzó en el útero de mi madre, ella fue mi primera narradora. Cuando nací, mi madre continuó deleitándome con sus hermosas historias donde príncipes y princesas y animales encantados siempre estuvieron presentes" (Emilia, 2019) 
Esta reconstrucción también se compone de búsquedas y preguntas, como en el extracto de la carta de Chapeuzinho Vermelho cuando no tiene estos recuerdos grabados: "Desafortunadamente, no recordaba ningún momento entre mí y un libro y un contador. Entonces les pregunté a mis padres si conocían a alguien en la familia que me contara historias, pero no había nadie" (Chapeuzinho Vermelho, 2019)

Otros registros revelan que la institución escolar tiene acceso a lo literario y que, sin este espacio de capacitación, el acceso de muchos estudiantes al universo literario estaría lejos de sus vidas.

Este universo de historias y lecturas me fue presentado en la escuela, los recuerdos más distantes que tengo son solo de la escuela primaria, donde "devoré" los libros de la biblioteca de Colégio Unidade Polo, donde asistí del quinto al octavo grado (Vagalume, 2019)

Las narraciones que se presentaron en estas cartas revelan la participación de narradores de historias en diferentes contextos y que tuvieron lugar en entornos escolares con acceso a espacios como bibliotecas y aulas. De las cartas iniciales, se puede ver que la figura del narrador está relacionada principalmente con figuras familiares, la madre o la abuela, a veces el padre o los hermanos. La siguiente tabla muestra quién introdujo el universo de la literatura a los profesores de investigación.

Tabla 3

Universo literario

\begin{tabular}{cc}
\hline PARTICIPANTE & QUIEN PRESENTÓ EL UNIVERSO DE LITERATURA \\
\hline Emília & Madre \\
Anna Llnas & No escribió la carta \\
Miudinha & No escribió la carta \\
Rei da Floresta & Abuela \\
Rita & Madre \\
Alice & Avó \\
Anjo & Madre \\
Inha Zabé & Madre \\
Disquinho & Madre \\
Sandra & Madre \\
Chapeuzinho Vermelho & Escuela \\
Maria & Hermana \\
A gata Borralheira & Padre \\
Rouxinol & Escuela \\
Vagalume & Escuela \\
Bela & No escribió la carta \\
Banqueiro & Madre \\
Barbie & Escuela \\
Arco-íris & Madre \\
Branca de Neve & Padre \\
Margarida & Abuelos \\
\hline
\end{tabular}

Fuente: elaboración propia, 2020

Estos son los narradores que presentaron el universo de la literatura a los maestros que participaron en el curso. Es posible determinar a partir de las cartas que la familia fue 
el mediador más grande en el universo literario de los maestros, de las 18 cartas recibidas, catorce de ellas registraron a un miembro de la familia como el que presentó el universo de la literatura. Y cuatro maestros tuvieron acceso a las historias en la escuela. Lo que muestra que la construcción de la educación literaria va más allá de la capacitación académica, las acciones de la infancia, a través de experiencias, los miembros de la familia muestran, como lo sugiere Vasconcelos (2000, p.12), que la identidad es: "forjar con múltiples hilos: relaciones familiares, clases, condiciones de género, características relacionadas con la edad, el origen étnico, la religiosidad, la ciudadanía y otros, cada uno matizado por anhelos, límites, rupturas y posibilidades".

La condición de acceso a las historias va mucho más allá de su educación académica y está llena de experiencias, el proceso de construcción del conocimiento, lo imaginario es una experiencia personal y, por esta misma razón, no es transferible. Las historias que marcaron la infancia de este grupo de maestros, en su mayoría son historias narradas, derivadas de los recuerdos de sus familiares como los siguientes casos:

Tenía muchas ganas de pasar mis vacaciones escolares en su sitio, porque sabía que me aventuraría en sus magníficas y viajadas porciones de historias; Estas historias a menudo se recrean a partir de situaciones, hechos reales o al menos similares a la realidad y adaptándose al mundo de la fantasía, es decir, historias de su propia autoría, por eso no tengo nombres, títulos como estos para informar aquí (Rei da floresta, 2019)

Hay registros de historias que fueron inventadas a través del folklore, con un enfoque en el miedo.

Descubrí el gusto por las historias cuando era pequeña y mi madre me contó sobre su infancia, sus juegos, su escuela, sus responsabilidades y el temido Hombre Lobo, esta narración era sagrada cuando llegó la Cuaresma, estaba aterrorizada por él. Pero me encantó escuchar a mi madre contar sus experiencias (Arco-íris, 2019)

La mayoría del grupo tenía historias infantiles tan clásicas como Chapeuzinho Vermelho, Os três porquinhos, Branca de Neve, A gata borralheira, O gato de botas, entre otros. En la tabla a continuación, registramos los temas y sus historias infantiles.

\section{Tabla 4}

Cuentos infantiles

\begin{tabular}{cc}
\hline PARTICIPANTE & HISTORIA PRESENTE EN LA INFANCIA \\
\hline Emília & Chapeuzinho Vermelho, Os três Porquinhos e O Patinho \\
Feio. \\
Anna Llnas \\
Miudinha & Não escreveu a carta. \\
Rei da Floresta & Não escreveu a carta. \\
Rita & Carta errante, avó atrapalhada e menina aniversariante. \\
O Gato de Botas, Chapeuzinho Vermelho e Os três \\
Porquinhos. \\
Anjo & Bambi \\
Inha Zabé & Chapeuzinho Vermelho e Branca de Neve e os Sete Anões. \\
Disquinho & Inha Isabé \\
& Branca de Neve, Chapeuzinho Vermelho e O gato de \\
& Botas.
\end{tabular}




$\begin{array}{cc}\text { Sandra } & \text { Os sete cabritinhos } \\ \text { Chapeuzinho Vermelho } & \text { Contos clássicos (não especificou quais) } \\ \text { Maria } & \text { Chapeuzinho Vermelho e Os três Porquinhos. } \\ \text { A gata Borralheira } & \text { Cinderela. } \\ \text { Rouxinol } & \text { Não indicou a história na carta. } \\ \text { Vagalume } & \text { Não tem memória de história na infância. } \\ \text { Bela } & \text { Não escreveu a carta. } \\ \text { Banqueiro } & \text { Vó Nana. } \\ \text { Barbie } & \text { Não tem memória de história na infância. } \\ \text { Arco-íris } & \text { A mentira cabeluda. } \\ \text { Branca de Neve } & \text { Branca de Neve e os sete anões. } \\ \text { Margarida } & \text { A margarida friorenta. }\end{array}$

Fuente: elaboración propia, 2020.

Al analizar las letras y enumerar las tablas 2 y 3 , es posible verificar que los maestros que tenían acceso a las historias solo en la escuela, no tenían un recuerdo de su historia infantil. Dado este hecho, es necesario que los maestros de educación de la primera infancia brinden momentos de acceso a la narración de cuentos, la lectura y los libros en todas las etapas de su trabajo. La educación inicial y continua emerge como una herramienta para explotar las posibilidades de acción, y más que eso, permite a aquellos que no tuvieron acceso en la infancia, momentos literarios con historias y libros que permitan el rescate de la imaginación, la fantasía y las aventuras. Corrobora el hecho de que

En la relación de formación y construcción de la identidad del narrador, permea la autoconciencia, la forma de entender la convivencia con el otro y la forma en que entendemos el mundo al que pertenecemos. Estos aspectos, por lo tanto, ayudan en la constitución de nuestra identidad (Vendrame, 2015, p. 109)

Como sugiere el extracto de la maestra

Todo cambió cuando me hice pasante en un CMEI de la ciudad. Sentí la necesidad de aprender canciones e historias para trabajar con los estudiantes. Me gustaba la literatura infantil y la literatura infantil era mi favorita en la graduación. Hoy, trabajando como maestra en educación infantil, disfruto leer, escuchar y contar cuentos infantiles. Aprendo mucho de mis amigos en el trabajo (Ruiseñor, 2019)

La formación inicial durante la graduación permitió descubrir el universo literario. El intercambio entre compañeros y sus prácticas ha mejorado su desempeño con los niños.

\section{CONSIDERACIONES FINALES}

Las cartas fueron un recurso importante utilizado en la recopilación de datos para reforzar y revelar los sentimientos y percepciones más personales e individuales de cada participante en el proceso. Además de registrar hechos que, por casualidad, no se revelaron en otros métodos de recolección, las cartas afectaron la imaginación de los participantes de la investigación, ya que se expresaron por escrito como lo deseaban.

El informe académico señala que el resultado positivo de los procesos de aprendizaje colaborativo en el área de la educación musical se debe en gran medida a la apertura del maestro, quien, incluso con la responsabilidad del liderazgo musical en el 
aula, puede ceder el control y asumir un rol de facilitador, colaborador en el proceso de aprendizaje, realizando una interacción y construcción de conocimiento junto con el alumno, que se siente más involucrado en el proceso.

Con respecto a la narración de historias, la investigación ha permitido comprender un proceso de relación con lo imaginario y la necesidad de una Educación Literaria que contemple los bienes culturales presentes en la sociedad. Mediada por las acciones experimentadas, se considera que la relación entre el arte de contar historias en la formación del profesorado, ya sea en los cursos de pregrado o de educación continua, es una acción importante que permite el acceso y la difusión de la cultura literaria, como un derecho humano esencial.

La narración de cuentos es una herramienta necesaria e importante para el proceso de enseñanza. Por lo tanto, como lo sugiere Freire (1996, p.23): "no hay enseñanza sin discurso", porque cuando asumes el rol de maestro, debes comprometerte con el aprendizaje constante, tomando conciencia del conocimiento que es necesario para la práctica pedagógica.

\section{REFERENCIAS BIBLIOGRÁFICAS}

Angrosino, M. (2008). Etnografia e Observação Participante. São Paulo: Artmed.

Azevedo, F. y Balça, Â. (2016). Educação literária e formação de leitores. En F. Azevedo y Â. Balça, (Coords.). Leitura e educação literaria (pp.1-13). Lisboa: Pactor.

Batista, I., y Paula, E. (2019) Cartas de professoras e alunas: narrativas sobre ausências e presenças da cultura afro-brasileira e africana no currículo escolar. En E. Paula, (org.). Cartas pedagógicas: revistando memórias e experiências em novos tempos. (pp. 75-89). Curitiba: CRV.

Bezerra, I. (2017). Aprendendo a ensinar coletivamente: A Aprendizagem Colaborativa na Musicalização Infantil na UFPB. En XI Conferência Regional Latino Americana de Educação Musical Da ISME, Natal.

Comério, M., y Brito, M. (2010). A Interação entre alunos no processo de solução de problemas matemáticos. X Encontro Nacional de Educação Matemática. Bahia.

Freire, V. B. (2010) Música, pesquisa e subjetividade: aspectos gerais. En V.B Freire. Horizontes da pesquisa em música (pp. 9-59). Rio de Janeiro: 7Letras.

Fugimoto, T. (2015). Composição musical com idosos: re-arranjando a Felicidade. 205f. Dissertação (Mestrado em Música - Educação Musical), Universidade do Estado de Santa Catarina, Centro de Artes, Programa de Pós-Graduação em Música, Florianópolis.

Gabriel, D. (2016). Música e Sociabilidade: Aprendizagem Colaborativa vs. Cooperativa. 133f. Dissertação (Mestrado em Ensino de Educação Musical no ensino Básico), Escola Superior de Educação, Departamento de Artes e Tecnologia, Coimbra.

Gonzaga, H. L. H. (2017). Sala de aula invertida: uma abordagem colaborativa na aprendizagem da matemática. Dissertação (Mestrado em Educação Matemática), programa Pós graduação em Educação, Universidade Federal de Juiz de Fora.

Goodsell, A. S. Maher, M. R.. y Tinto, V. (1992). Collaborative learning: a sourcebook for Higher Education. National Center on Postsecondary Teaching, Learning and Assessment: University Park, PA. 
Graça, T. (2016). A aprendizagem colaborativa no contexto do ensino-aprendizagem de português língua estrangeira. Dissertação (Mestrado em Português - Segunda língua estrangeira), Universidade do porto.

Gray, D. E. (2011). Pesquisa no mundo real. Métodos de Pesquisa. Porto Alegre: Penso.

Machado, D. A. O. (2017). Aprendizagem criativa-colaborativa e liderança musical: princípios e práticas. 107f. Dissertação (Mestrado em Música - Educação Musical). Programa de pós-graduação em Música da Universidade Federal de Minas Gerais, Belo Horizonte.

Marsh, K. (2013). Exploring children's musical play. En P. Burnard y R. Murphy. Teaching music creatively. Londo:Routledg, p.12

Moraes, A. y Castro, F. (2018) Por uma estetização da escrita acadêmica: poemas, cartas e diários envoltos em intenções pedagógicas. Revista Brasileira de Educação, 23. doi: 10.1590/s1413-24782018230091.

Moraes, A., y Paiva, D. (2018). Cartas pedagógicas: reflexões de docente da educação básica e ensino superior. Fortaleza: EdUECE.

Oliveira, A. (2015). "A gente ensina, aprende e inventa, tudo de uma vez": as aprendizagens colaborativas nas brincadeiras cantadas e jogos musicais numa oficina de música com crianças. 255f. Dissertação (Mestrado em Música Educação Musical), Universidade do Estado de Santa Catarina, Centro de Artes, Programa de Pós-Graduação em Música, Florianópolis.

Oliveira, Z. M.R., Silva, A. P.S., Cardoso, F. M. y Augusto, S. O. (2006). Construção da identidade docente: relatos de educadores de educação infantil. Cadernos de Pesquisa, 36(129), pp. 547-571. Disponible en: http://www.scielo.br/pdf/cp/ v36n129/a0336129.pdf.

Paula, E. (org). (2018). Cartas pedagógicas: estratégias didáticas revisitadas para novos tempos. Curitiba, CRV.

Renshaw, P. (2013) Collaborative learning: a catalyst for organizational development in higher music education. En H. Gaunt y H. Westerlund, H. (Eds.). Collaborative learning in higher music education. Surrey, (pp. 237-267). UK: Ashgate.

Ribeiro, M. y Ramos, M. (2012). Grupos Colaborativos como estratégia de aprendizagem em aulas de química. Acta Scientiae, 14(3), 456-471.

Roig-Rechou, B. (2013). Educação literária e Literatura Infanto-juvenil. Porto: Editora Tropelias \& Companhia.

Seixas, J. (2001). Percursos de memória em terras de história: problemáticas atuais. En S. Bresciani y M Naxara (Orgs.). Memória e (res)sentimento: indagações sobre uma questão sensível, (pp. 37-58). Campinas-SP: Unicamp.

Smith, B. y Leigh. M. (1992). What is Collaborative Learning? En Goodsell, Maher, Tinto. Collaborative learning: a sourcebook for Higher Education. National Center on Postsecondary Teaching, Learning and Assessment. Pennsylvania: University Park. 9-22

Torres, P. y Esrom A. (2014). Aprendizagem Colaborativa: Teoria e Prática. En P. Torres. (Org.). Metodologias para a Produção do Conhecimento: da concepção à prática (pp. 61-93). Curitiba: SENARPR.

Troncareli, M., y Faria, A. (2014). A aprendizagem colaborativa para a interdependência positiva no processo ensino aprendizagem em cursos universitários. Educação, Santa Maria, 39(2), 427-444. 
Vasconcelos, G. (2000) Puxando um fio. En G. Vasconcelos (Org). Como me fiz professora. (pp. 07-19). Rio de Janeiro: DP\&A.

Vendrame, E. C. dos S. (2015). Da história contada ao sujeito da contação: como me fiz contadora de história... (132 f). Dissertação (Mestrado em Educação) Universidade Estadual de Maringá. Orientadora: Dra . Ercília Maria Angeli Teixeira de Paula. Maringá.

Vigotski, L. S. (2009). Imaginação e criação na infância. São Paulo: Ática.

Warschauer, C. (2017). Rodas em rede: oportunidades formativas na escola e fora dela. Rio de Janeiro: Paz e Terra. 